\title{
Self-tuning Experience Weighted Attraction Learning in Games
}

\author{
Teck H. Ho, Colin F. Camerer, and Juin-Kuan Chong ${ }^{1}$
}

November 11, 2005

\footnotetext{
${ }^{1}$ Ho: Haas School of Business, University of California, Berkeley, Berkeley, CA 94720-1900, hoteck@haas.berkeley.edu. Camerer: Division of Humanities and Social Sciences, California Institute of Technology, Pasadena, CA 91125, camerer@hss.caltech.edu. Chong: National University of Singapore, 1 Business Link, Singapore 117951, bizcjk@nus.edu.sg. Direct correspondence to the first author. Thanks to participants in the 2000 Southern Economics Association meetings, the Wharton School Decision Processes Workshop, the University of Pittsburgh, the Berkeley Marketing Workshop, the Nobel Symposium on Behavioral and Experimental Economics (December 2001) and C. Mónica Capra, David Cooper, Vince Crawford, Ido Erev, Guillaume Frechette, and anonymous referees for helpful comments.
} 


\begin{abstract}
Self-tuning experience weighted attraction (EWA) is a one-parameter theory of learning in games. It addresses a criticism that an earlier model (EWA) has too many parameters, by fixing some parameters at plausible values and replacing others with functions of experience so that they no longer need to be estimated. Consequently, it is econometrically simpler than the popular weighted fictitious play and reinforcement learning models.

The functions of experience which replace free parameters "self-tune" over time, adjusting in a way that selects a sensible learning rule to capture subjects' choice dynamics. For instance, the self-tuning EWA model can turn from a weighted fictitious play into an averaging reinforcement learning as subjects equilibrate and learn to ignore inferior foregone payoffs. The theory was tested on seven different games, and compared to the earlier parametric EWA model and a one-parameter stochastic equilibrium theory (QRE). Self-tuning EWA does as well as EWA in predicting behavior in new games, even though it has fewer parameters, and fits reliably better than the QRE equilibrium benchmark.
\end{abstract}




\section{Introduction}

The power of equilibrium models of games comes from their ability to produce precise predictions using only the structure of a game and assumptions about players' rationality. Statistical models of learning, on the other hand, often need data to calibrate free parameters in order to generate predictions about behavior in new games. This calibration-prediction process, while standard in econometrics, gives rise to two unresolved issues for learning models: the value of additional parameters in a generalized model, and explaining apparent cross-game variation in learning rules.

The first unresolved issue is how to judge the value of incremental parameters when comparing models with different numbers of parameters. For example, the EWA learning model (Camerer and Ho, 1999) econometically nests the weighted fictitious play (Fudenberg and Levine, 1998) and averaging reinforcement learning (Erev and Roth, 1998) models, As a result, the EWA model has 2 and 3 more parameters than weighted fictitious play and averaging reinforcement learning, respectively. There are many standard statistical procedures for comparing models with different numbers of parameters. One popular approach is generalized likelihood ratio tests which penalize theories for extra free parameters (e.g., the Akaike or Bayesian informaton criteria). Another approach is to judge the predictive power of a learning model out-of-sample (i.e., after parameter values have been estimated) in both existing and brand new games. The results from prior studies suggest that the additional parameters in EWA are helpful in improving predictions of behavior at least in some games, by either Bayesian information criteria or out-of-sample fit (e.g., Camerer, Ho and Chong, 2002).

In this paper we take a different approach: By reducing the number of estimated parameters in the EWA model. Ideally, the methods used to reduce parameters are behaviorally principled and insightful. We reduce parameters in two ways: Fixing parameters to specific numerical values; and replacing estimable parameters with functions of data.

Fixing a parameter value numerically can reduce the general EWA specification. There are two parameter restrictions which reduce general EWA learning models so that they still include many familiar special cases. It is also helpful to replace the free parameters which represent the initial strengths of strategies, rather than estimating them, because initial conditions are not of central interest in studying learning (their initial impact typically declines rapidly as learning takes place). We replace estimation of initial conditions with a priori numerical values derived 
from a cognitive hierarchy model that was designed to predict how people play one shot games (Camerer, Ho, and Chong, 2004), although other models could be used instead.

Replacing a free parameter with a function which depends on observed experience means the parameter does not have to be estimated from data. The functional value can also vary over time, games, and different players. The key for these functions to fit well and to generate insight lies in using behaviorally plausible principles to derive the functional forms. We use this functional approach to replace parameters that represent the decay weights placed on recent and distant experience, and the weight placed on foregone payoffs from strategies that were not chosen.

By replacing three EWA parameters with sensibly determined numerical values and two EWA parameters with behaviorally disciplined functions of experience, the resulting self-tuning EWA model has only one free parameter, fewer than typical versions of reinforcement and weighted fictitious play models. The goal is to make the self-tuning EWA model as predictive as the original parametric EWA model while reducing the number of parameters as much as possible.

The second unresolved issue is how to model cross-game variation in parameters of learning theories. Several studies have shown that the best-fitting parameter values of learning rules vary significantly across games and across subjects (see for example Yin-Wong Cheung and Daniel Friedman, 1997 and Colin Camerer and Teck Ho, 1999; for a comprehensive review, see Camerer, 2003). Some learning theorists regard parameter variation across games as a "disappointment" (e.g., Guillaume Frechette, 2003, p. 42). We disagree and regard variation across games as a natural reflection of the heterogeneity in the learning environment (as determined by the game structure and the history of play). Modelling cross-game variation should be viewd as a scientific challenge.

One could abandon the search for a single rule that predicts well across games, and instead build up a catalog of which rules fit well in which games. We do otherwise, by developing a learning model which flexibly "self-tunes" the parameters of our earlier EWA model across game, subjects, and time (inspired by self-tuning control and Kalman filtering ${ }^{2}$ ). The model

\footnotetext{
${ }^{2}$ Erev, Bereby-Meyer and Roth (1999) use a response sensitivity parameter which is "self-adjusting" in a similar way. They divide the fixed parameter ( $\lambda$ in the notation below) by the average absolute deviation of received payoffs from historically average payoff. As a result, when equilibration occurs the payoff variance shrinks and the adjusted $\lambda$ rises, which sharpens convergence to equilibrium. (This remedies a problem noted by Jasmina
} 
posits a single family of self-tuning functions which can be applied to a wide variety of games. The functions are the same in all games, but the interaction of game structure and experience will generate different parameter values from the functions, both across games and across time within a game. We find that the self-tuning functions can reproduce parameter variation well enough that the model out-predicts models which estimate separate parameters for different games, in forecasting behavior in new games.

Since many familiar learning rules correspond to particular values of decay and foregone payoff weights, endogeneous changes in these parameters through their functional forms in selftuning EWA also creates variation in rules over time, a reduced-form variant of "rule learning". 3 One key function is the decay rate $\phi_{i}(t)$, which weights previous experience. The self-tuning value of $\phi_{i}(t)$ falls when another player's behavior changes sharply (a kind of deliberate forgetting resulting from change-detection or surprise). This change is like switching from a pure fictitious play belief learning rule (which weights all past experience equally) to a rapidly-adjusting Cournot belief learning rule (which weights only the last period and ignores previous periods). The change captures the idea that if their opponents are suddenly behaving differently than in the past, players should ignore their distant experience and concentrate only on what happened recently. (Albert Marcet and Juan Pablo Nicolini, 2004, use a similar change-detection model to explain learning in repeated monetary hyperinflations).

The second key function is the weight given to foregone payoffs, $\delta_{i j}(t)$, in updating the numerical attractions of strategies. This weight is one for strategies that yield better or equal payoffs than the payoff a player actually received, and zero for strategies that yield worse than actual payoffs. If players start out choosing bad strategies, then the weights on most alternative strategies are 1, and the rule is approximately the same as belief learning (i.e., reinforcing all strategies' payoffs equally). But when players are in a strict pure-strategy equilibrium, all other strategies have worse payoffs and so the rule is equivalent to choice reinforcement.

While the self-tuning EWA model is honed on data from several game experiments, it should be of interest to economists of all sorts because learning is important for virtually every area

Arifovic and John Ledyard, 2002- in games with many strategies, learning models predict less convergence in strategy frequencies than is observed.) Their model also has the interesting property that when the game changes and received payoffs suddenly change, the adjusted $\lambda$ rises, flattening the profile of choice probabilities which causes players to "explore" their new environment more.

${ }^{3}$ Variation over time in EWA might be more aptly called rule adjustment. It is different than directly reinforcing different rules according to payoffs of strategies those rules recommend, as in Stahl, 2000. 
of economics. ${ }^{4}$ Much as in physical sciences, in the lab we can see clearly how various theories perform in describing behavior (and giving valuable advice) before applying those theories to more complex field applications. Since self-tuning EWA is designed to work across many economic domains, sensible extensions of it could be applied to field settings such as evolution of economic institutions (e.g., internet auctions or pricing), investors and policymakers learning about equity market fluctuations or macroeconomic phenomena (as in Allan Timmerman, 1993, or Marcet and Nicolini, 2004), and consumer choice (e.g., Ho and Juin-Kuan Chong, 2003).

The paper is organized as follows. In the next section, we describe the self-tuning EWA model and its parametric precursor. In section 3, self-tuning EWA is used to fit and predict data from seven experimental data sets. The hardest kind of prediction is to estimate free parameters on one sample of games and predict play in a new game. Self-tuning EWA does well in this kind of cross-game prediction. Section 4 concludes.

\section{Self-tuning EWA}

First, some notation is necessary. For player $i$, there are $m_{i}$ strategies, denoted $s_{i}^{j}$ (the $j$-th strategy for player $i$ ), which have initial attractions denoted $A_{i}^{j}(0)$. Strategies actually chosen by $i$ in period $t$, and by all other players (who are denoted $-i$ ) are $s_{i}(t)$ and $s_{-i}(t)$ respectively.

\footnotetext{
${ }^{4}$ Since its first exposition in 2001, the self tuning model has succeeded in many robustness tests in which other researchers applied the model to many games that are substantially different from the seven games we validated the model on in this paper. We highlight three pieces of work here: Kocher and Sutter (2005) data stretches the model to explain choices made by groups; Cabrales, Nagel, and Armenter (2002) and Sovik (2001) are games of incomplete information (All seven games we studied are games with complete information.)

Kocher and Sutter (2005)'s data are choices made by individual and three-person groups in p-beauty contests. Competing groups appear to learn much faster than individuals. Cabrales, Nagel, and Armenter (2002) report data from a 2x2 coordination game with incomplete information, studying theories of "global games". In their games, players receive a private signal (knowing the distribution of private signals) which shows the payoffs in a signal-dependent stag-hunt coordination game. The game was designed so that iterated dominance leads subjects to select the risk-dominant outcome. Sovik (2001) reports data from a zero-sum betting game with asymmetric information. Two players simultaneously choose between a safe outside option and a zero-sum game based on their information sets. The information sets were chosen such that the game is dominance solvable. Players should figure out that they should never bet because they can only bet against players with better information. The self-tuning model fits the data well in all three datasets. Specific estimation result is available in our longer working paper version or by request. We have also recently extended the self-tuning model to study sophistication and quantal response equilibrium in repeated trust and entry games (Chong, Ho and Camerer, in press).
} 
Player $i$ 's ex-post payoff of choosing strategy $s_{i}^{j}$ in time $t$ is $\pi_{i}\left(s_{i}^{j}, s_{-i}(t)\right)$ and the actual payoff received is $\pi_{i}\left(s_{i}(t), s_{-i}(t)\right) \equiv \pi_{i}(t)$.

For player $i$, strategy $j$ has a numerical attraction $A_{i}^{j}(t)$ after updating from period $t$ experience. $A_{i}^{j}(0)$ are initial attractions before the game starts. Attractions determine choice probabilities in period $t+1$ through a logistic stochastic response function, $P_{i}^{j}(t+1)=\frac{e^{\lambda \cdot A_{i}^{j}(t)}}{\sum_{k=1}^{m_{i}} e^{\lambda \cdot A_{i}^{k}(t)}}$, where $\lambda$ is the response sensitivity. Note that $\lambda=0$ is random response and $\lambda=\infty$ is bestresponse.

In the parametric EWA model, attractions are updated by

$$
A_{i}^{j}(t)=\frac{\phi \cdot N(t-1) \cdot A_{i}^{j}(t-1)+\left[\delta+(1-\delta) \cdot I\left(s_{i}^{j}, s_{i}(t)\right)\right] \cdot \pi_{i}\left(s_{i}^{j}, s_{-i}(t)\right)}{N(t-1) \cdot \phi \cdot(1-\kappa)+1}
$$

where $I(x, y)$ is an indicator function (equal to zero if $x \neq y$ and one if $x=y$ ) (see Camerer and Ho, 1999). That is, previous attractions are multiplied by an experience weight $N(t-1)$, decayed by a weight $\phi$, incremented by either the payoff received (when $I\left(s_{i}^{j}, s_{i}(t)\right)=1$ ) or by $\delta$ times the foregone payoff (when $I\left(s_{i}^{j}, s_{i}(t)\right)=0$ ), and pseudo-normalized.

EWA is a hybrid of the central features of reinforcement and fictitious play (belief learning) models. This hybrid is useful if actual learning mixes components of those simpler rules. A hybrid is also useful for evaluating the statistical and economic advantages of complicating the simpler models by adding components (and, consequently, for finding out when simple rules are adequate approximations and when they are not).

Standard reinforcement models assume that only actual choices are reinforced (i.e., $\delta=0) .^{5}$ When $\delta=0$ and $\kappa=1$ the rule is like the cumulative reinforcement model of Roth and Erev (1995). When $\delta=0$ and $\kappa=0$ it is like the averaging reinforcement model of Erev and Roth (1998). A central insight from the EWA formulation is that weighted fictitious play belief learning is exactly the same as a generalization of reinforcement in which all foregone payoffs

\footnotetext{
${ }^{5}$ See Calvin Harley (1981), Roth and Erev (1995), Sarin and Vahid (2001) (cf. Robert R. Bush and Frederick Mosteller, 1955; John Cross, 1983; Patrick McAllister, 1991; Brian Arthur, 1991). Choice reinforcement is most sensible when players do not know the foregone payoffs of unchosen strategies. However, several studies show that providing foregone payoff information affects learning (See Dilip Mookerjhee and Barry Sopher (1994), Amnon Rapoport and Erev (1998), and John Van Huyck, Ray Battalio and Frederick Rankin (2005)), which suggests that players do not simply reinforce chosen strategies. Rajiv Sarin and Farshid Vahid, 2003, show that "spilling" over payoff reinforcement to neighboring strategies can explain the rapid pace of learning in the Van Huyck et al. (1996) game.
} 
are reinforced by a weight $\delta=1$ (when $\kappa=0) .{ }^{6}$ Intuitively, the EWA form allows both the stronger focus on payoffs that are actually received, as in reinforcement (i.e., $\delta<1$ ) and the idea that foregone payoffs usually affect learning when they are known, as in fictitious play (i.e., $\delta>0$ ). Figure 1 is a cube that shows the universe of learning rules captured by the EWA learning model and the positions of various familiar cases.

As shown in Figure 1, the front face of the cube $(\kappa=0)$ captures almost all familiar special cases except for the cumulative reinforcement model. The cumulative model has been supplanted by the averaging model (with $\kappa=0$ ) because the latter seems to be more robust in predicting behavior in some games (see Erev and Roth 1998). This sub-class of EWA learning models is the simplest model that nests averaging reinforcement and weighted ficititous play (and hence Cournot and simple fictitious play) as special cases. It can also capture a weighted fictitious play model using time-varying belief weights (such as the stated-beliefs model explored by Yaw Nyarko and Andy Schotter, 2002), as long as subjects are allowed to use a different weight to decay lagged attractions over time (i.e., move along the top edge of the side in Figure 1 ). There is also an empirical reason to set $\kappa$ to a particular value. Our prior work suggests that $\kappa$ does not seem to affect fit much (e.g., Camerer and Ho, 1999; Ho, Xin Wang, and Camerer, 2004).

The initial experience $N(0)$ was included in the original EWA model so that Bayesian learning models are nested as a special case $-N(0)$ represents the strength of prior beliefs. We restrict $N(0)=1$ here because its influence fades rapidly as an experiment progresses and most subjects come to experiments with weak priors anyway. The specification of initial attractions is not specific to a learning rule. All learning rules that use attraction as latent variable to predict behavior must face with this problem. We use a "cognitive hierarchy" $(\mathrm{CH})$ theory of games (Camerer, Ho and Chong, 2004) to provide the initial attraction values because it has been shown to predict behavior well in many one-shot games. In the $\mathrm{CH}$ theory, each player assumes that his strategy is the most sophisticated. The $\mathrm{CH}$ model has a hierarchy of categories: step 0 players randomize; and step $k$ thinkers best-respond, assuming that other players are distributed over step 0 through step $k<1$. Since an average of 1.5 steps fits data well from many games, we use that value to set initial attractions. ${ }^{7}$

\footnotetext{
${ }^{6}$ See also Cheung and Friedman, 1997, pp. 54-55; Drew Fudenberg and David Levine, 1998, pp. 1084-1085; Ed Hopkins, 2002.

${ }^{7}$ There are at least three other ways to pin down the initial attractions $A_{i}^{j}(0)$. You can either use the first-period data to "burn-in" the attractions, assume all initial attractions are equal (which leads to uniformlydistributed first-period choices), or assume players use a decision rule that best-responds to a uniform distribution.
} 
Consequently, we are left with three free parameters- $\phi, \delta$, and $\lambda$. To make the model simple to estimate statistically, and self-tuning, the parameters $\phi$ and $\delta$ are replaced by deterministic functions $\phi_{i}(t)$ and $\delta_{i j}(t)$ of player $i$ 's experience with strategy $j$, up to period $t$. These functions determine numerical parameter values for each player, strategy, and period, which are then plugged into the EWA updating equation above to determine attractions in each period. Updated attractions determine choice probabilities according to the logit rule, given a value of $\lambda$. Standard maximum-likelihood methods for optimizing fit can then be used to find which $\lambda$ fits best. ${ }^{8}$

\subsection{The change-detector function $\phi_{i}(t)$}

The decay rate $\phi$ which weights lagged attractions is sometimes called "forgetting" (an interpretation which is carried over from reinforcement models of animal learning). While forgetting obviously does occur, the more interesting variation in $\phi_{i}(t)$ across games, and across time within a game, is a player's perception of how quickly the learning environment is changing. The function $\phi_{i}(t)$ should therefore "detect change". When a player senses that other players are changing, a self-tuning $\phi_{i}(t)$ should dip down, putting less weight on distant experience. As in physical change detectors (e.g., security systems or smoke alarms), the challenge is to detect change when it is really occurring, but not falsely mistake small fluctuations for real changes too often.

The core of the $\phi_{i}(t)$ change-detector function is a "surprise index", which is the difference between other players' recent strategies and their strategies in previous periods. First define a history vector, across the other players' strategies $k$, which records the historical frequencies (including the last period $t$ ) of the choices by other players. The vector element $h_{i}^{k}(t)$ is $\frac{\sum_{\tau=1}^{t} I\left(s_{-i}^{k}, s_{-i}(\tau)\right)}{t} .{ }^{9}$ The recent 'history' $r_{i}^{k}(t)$ is a vector of 0's and 1's which has a one for

strategy $s_{-i}^{k}=s_{-i}(t)$ and 0 's for all other strategies $s_{-i}^{k}$ (i.e., $\left.r_{i}^{k}(t)=I\left(s_{-i}^{k}, s_{-i}(t)\right)\right)$. The

The cognitive hierarchy approach uses a specific mixture of the latter two rules but adds further steps of iterated thinking in a precise way. Stahl and Wilson (1995) and Costa-Gomes, Crawford and Broseta (2001) explore richer reasoning-step models.

${ }^{8}$ If one is interested only in the hit rate- the frequency with which the predicted choice is the same as what a player actually picked- then it is not necessary to estimate $\lambda$. The strategy that has the highest attraction will be the predicted choice. The response sensitivity $\lambda$ only dictates how frequently the highest-attraction choice is actually picked, which is irrelevant if the statistical criterion is hit rate.

${ }^{9}$ Note that if there is more than one other player, and the distinct choices by different other player's matter to player $i$, then the vector is an $n-1$ - dimensional matrix if there are $n$ players. 
surprise index $S_{i}(t)$ simply sums up the squared deviations between the cumulative history vector $h_{i}^{k}(t)$ and the immediate recent history vector $r_{i}^{k}(t)$; that is,

$$
S_{i}(t)=\sum_{k=1}^{m_{-i}}\left(h_{i}^{k}(t)-r_{i}^{k}(t)\right)^{2} .
$$

In other words, the surprise index captures the degree of change of the most recent observation ${ }^{10}$ from the historical average. Note that it varies from zero (when the last strategy the other player chose is the one they have always chosen before) to two (when the other player chose a particular strategy 'forever' and suddenly switches to something brand new). When surprise index is zero, we have a stationary environment; when it is one, we have a turbulent environment. The change-detecting decay rate is:

$$
\phi_{i}(t)=1-\frac{1}{2} \cdot S_{i}(t)
$$

Because $S_{i}(t)$ is between zero and two, $\phi$ is always (weakly) between one and zero.

Some numerical boundary cases help illuminate how the change-detection works. If the other player chooses the strategy she has always chosen before, then $S_{i}(t)=0$ (player $i$ is not surprised) and $\phi_{i}(t)=1$ (player $i$ does not decay the lagged attraction at all, since what other players did throughout is informative). The opposite case is when an opponent has previously chosen a single strategy in every period, and suddenly switches to a new strategy. In that case, $\phi_{i}(t)$ is $\frac{2 t-1}{t^{2}}$. This expression declines gracefully toward zero as the string of identical choices up to period $t$ grows longer. (For $t=2,3,5$ and 10 the $\phi_{i}(t)$ values are $.75, .56, .36$, and .19.) The fact that the $\phi$ values decline with $t$ expresses the principle that a new choice is bigger surprise (and should have an associated lower $\phi$ ) if it follows a longer string of identical choices which are different from the surprising new choice. Note that since the observed behavior in period $t$ is included in the history $h_{i}^{k}(t), \phi_{i}(t)$ will never dip completely to zero. (which could be a mistake because it erases all the history embodied in the lagged attraction). For example, if a player chose the same strategy for each of 19 periods and a new strategy in period 20, then $\phi_{i}(t)=39 / 400=.0975$.

Another interesting special case is when unique strategies have been played in every period up to $t-1$, and another unique strategy is played in period t. (This is often true in games

\footnotetext{
${ }^{10}$ In games with mixed equilibria (and no pure equilibria), a player should expect other players' strategies to vary. Therefore, if the game has a mixed equilibrium with $W$ strategies which are played with positive probability, the surprise index defines recent history over a window of the last $W$ periods (e.g., in a game with four strategies that are played in equilibrium, $W=4)$. Then $r_{i}^{k}(t)=\sum_{k=1}^{m_{-i}}\left[\frac{\sum_{\tau=t-W+1}^{t} I\left(s_{-i}^{k}, s_{-i}(\tau)\right)}{W}\right]$.
} 
with large strategy spaces.) Then $\phi_{i}(t)=.5+\frac{1}{2 t}$, which starts at .75 and asymptotes at .5 as $t$ increases. Comparing the case where the previous strategy was the same, and the previous strategies were all different, it is evident that if the choice in period $t$ is new, the value of $\phi_{i}(t)$ is higher if there were more variation in previous choices, and lower if there were less variation. This mimicks a hypothesis-testing approach (cf. Marcet and Nicolini, 2003) in which more variation in previous strategies implies that players are less likely to conclude there has been a regime shift, and therefore do not lower the value of $\phi_{i}(t)$ too much.

Note that the change-detector function $\phi_{i}(t)$ is individual and time specific and it depends on information feedback. Nyarko and Schotter (2002) show that a weighted fictitious play model that uses stated beliefs (instead of empirical beliefs posited by the fictitious play rule) can predict behavior better than the original EWA model in games with unique mixed-strategy equilibrium. One way to intrepret their result is that their model allows each subject to attach a different weight to previous experiences over time. In the same vein, the proposed changedetector function allows for individual and time heterogeneity by positing them theoretically.

\subsection{The attention function, $\delta_{i j}(t)$}

The parameter $\delta$ is the weight on foregone payoffs. Presumably this is tied to the attention subjects pay to alternative payoffs, ex-post. Subjects who have limited attention are likely to focus on strategies that would have given higher payoffs than what was actually received, because these strategies present missed opportunities (cf. Sergiu Hart and Andreu Mas-Collel (2001), who show that such a regret-driven rule converges to correlated equilibrium.) To capture this property, define ${ }^{11}$

$$
\delta_{i j}(t)= \begin{cases}1 & \text { if } \pi_{i}\left(s_{i}^{j}, s_{-i}(t)\right) \geq \pi_{i}(t) \\ 0 & \text { otherwise }\end{cases}
$$

That is, subjects reinforce chosen strategies and all unchosen strategies with (weakly) better payoffs by a weight of one. They reinforce unchosen strategies with strictly worse payoffs by zero.

\footnotetext{
${ }^{11}$ In games with unique mixed-strategy equilibrium, we use $\delta_{i j}(t)=\frac{1}{W}$ if $\pi_{i}\left(s_{i}^{j}, s_{-i}(t)\right) \geq \pi_{i}(t)$ and 0 otherwise. This modification is driven by the empirical observation that estimated $\delta$ 's are often close to zero in mixed games (which might also be due to misspecified heterogeneity, see Nathaniel Wilcox, 2003). Using only $\delta_{i j}(t)$ without this adjustment produces slightly worse fits in the two mixed-equilibrium games examined below where the adjustment matters (patent-rate games and the Mookerjhee-Sopher games).
} 
Note that this $\delta_{i j}(t)$ can transform the self-tuning rule into special cases over time. If subjects are strictly best-responding (ex post), then no other strategies have a higher ex-post payoff so $\delta_{i j}(t)=0$ for all strategies $j$ which were not chosen, which reduces the model to choice reinforcement. However if they always choose the worst strategy, then $\delta_{i j}(t)=1$, which corresponds to weighted fictitious play. If subjects neither choose the best nor the worst strategy, the updating scheme will push them (probabilistically) towards those strategies that yield better payoffs, as is both characteristic of human learning and normatively sensible.

The updating rule is a natural way to formalize and extend the "learning direction" theory of Selten and Stoecker (1986). Their theory consists of an appealing property of learning: Subject move in the direction of ex-post best-response. Broad applicability of the theory has been hindered by defining 'direction' only in terms of numerical properties of ordered strategies (e.g., choosing 'higher prices' if the ex-post best response is a higher price than the chosen price). The self-tuning $\delta_{i j}(t)$ defines the 'direction' of learning set-theoretically, as shifting probability toward the set of strategies with higher payoffs than the chosen ones.

The self-tuning $\delta_{i j}(t)$ also creates the "exploration-exploitation" shift in machine learning (familiar to economists from multi-armed bandit problems). In low-information environments, it makes sense to explore a wide range of strategies, then gradually lock in to a choice with a good historical relative payoffs. In self-tuning EWA, if subjects start out with a poor choice, many unchosen strategies will be reinforced by their (higher) foregone payoffs, which shifts choice probability to those choices and captures why subjects "explore". As equilibration occurs, only the chosen strategy will be reinforced, thereby producing an "exploitation" or "lock-in" (cf. Erev et al., 1999). This is behaviorally very plausible. The updating scheme also helps to detect any change in environment. If a previously optimal response becomes inferior because of an exogenous change, other strategies will have higher ex-post payoffs, triggering higher $\delta_{i j}(t)$ values (and reinforcement of superior payoffs) and guiding players to re-explore better strategies.

The self-tuning $\delta_{i j}(t)$ function can also be seen as a reasonable all-purpose rule which conserves a scarce cognitive resource- attention. The hybrid EWA model showed that weighted fictitious play is equivalent to generalized reinforcement in which all strategies are reinforced. But reinforcing many strategies takes attention. As equilibration occurs, the set of strategies which receive positive $\delta_{i j}(t)$ weights shrinks so attention is conserved when spreading attention widely is no longer useful. When an opponent's play changes suddenly, the self-tuning $\phi_{i}(t)$ value drops. This change reduces attractions (since lagged attractions are strongly decayed) and 
spreads choice probability over a wider range of strategies due to the logit response rule. This implies that the strategy chosen may no longer be optimal, leading $\delta_{i j}(t)$ to allocate attention over a wider range of better-responses. Thus, the self-tuning system can be seen as procedurally rational (in Herbert Simon's language) because it follows a precise algorithm and is designed to express the basic features of how people learn- by exploring a wide range of options, locking in when a good strategy is found, but re-allocating attention when environmental change demands such action.

A theorist's instinct is to derive conditions when flexible learning rules choose parameters optimally, which is certainly a direction to explore in future research (cf. Dana Heller and Sarin, 2000; Jens Josephson, 2001). However, broadly-optimal rules will likely depend on the set of games an all-purpose learning agent encounters, and also may depend sensitively on how cognitive costs are specified (and should also jibe with data on the details of neural mechanisms, which are not yet well-understood). So it is unlikely to find a universally optimal rule that can always beat rules which adapt locally.

Our approach is more like exploratory work in machine learning. Machine learning theorists try to develop robust heuristic algorithms which learn effectively in a wide variety of lowinformation environments (see Sutton and Barto 1998). Good machine learning rules are not provably optimal but perform well on tricky test cases and natural problems like those which good computerized robots need to perform (navigating around obstacles, hill-climbing on rugged landscapes, difficult pattern recognition, and so forth).

Before proceeding to estimation, it is useful to summarize the properties of the self-tuning model. First, the use of simple fictitious play and reinforcement theories in empirical analysis are often justified by the fact that they have few free parameters. The self-tuning EWA is useful by this criterion as well because it requires estimating only one parameter, $\lambda$ (which is difficult to do without in empirical work). Second, the functions in self-tuning EWA naturally vary across time, people, games, and strategies. The potential advantage of this flexibility is that the model can predict across new games better than parametric methods. Whether this advantage is realized will be examined below. Third, the self-tuning parameters can endogenously shift across rules. Early in a game, when opponent choices vary a lot and players are likely to make ex-post mistakes, the model automatically generates low values of $\phi_{i}(t)$ and high $\delta_{i j}(t)$ weights- it resembles Cournot belief learning. As equilibration occurs and behavior of other players stabilizes, $\phi_{i}(t)$ rises and $\delta_{i j}(t)$ falls- it resembles reinforcement learning. The model therefore keeps a short window of history (low $\phi$ ) and pays a lot of attention (high $\delta$ ) when it 
should, early in a game, and conserves those cognitive resources by remembering more (high $\phi$ ) and attending to fewer foregone strategies (low $\delta$ ) when it can afford to, as equilibration occurs.

\section{Self-tuning EWA predictions within and across games}

In this section we compare in-sample fit and out-of-sample predictive accuracy of self-tuning EWA, its predecessor (EWA) where parameters are freely estimated, and the one-parameter Quantal Response Equilibrium model benchmark (Richard McKelvey and Thomas Palfrey, 1995). ${ }^{12}$ The goal is to see whether self-tuning EWA functions can produce game-specific parameters which are similar to values estimated separately in different games. In addition, we use a jackknife approach by estimating a common set of parameters on $n-1$ of the $n$ games and use the estimated parameters to predict choices in the remaining game, to judge how well models predict across games (cf. Erev and Roth, 1998).

We use seven games: Two matrix games with unique mixed strategy equilibrium (Dilip Mookerjhee and Barry Sopher, 1997); R\&D patent race games (Amnon Rapoport and Wilfred Amaldoss, 2000); a median-action order statistic coordination game with several players (John Van Huyck, Ray Battalio, and Richard Beil, 1990); a continental-divide coordination game, in which convergence behavior is extremely sensitive to initial conditions (Van Huyck, Joseph Cook, and Battalio, 1997); a coordination game in which players choose whether to enter a large or small market (Amaldoss and Ho, 2001); dominance-solvable p-beauty contests (Ho, Camerer, and Keith Weigelt, 1998); and a price matching game called traveler's dilemma (Monica Capra, Jacob Goeree, Rosario Gomez and Charles Holt, 1999).

Table 1 summarizes features of these games and the data. Three of the games are described in detail below. ${ }^{13}$ Many different games are studied because a main goal is to see how well

\footnotetext{
${ }^{12}$ Our working paper also reports fit statistics and estimates from belief learning and reinforcement models.

${ }^{13}$ The other four games are: Mixed-equilibrium games studied by Mookerjhee and Sopher (1997) which have four or six strategies, one of which is weakly-dominated; the nine-player median-action game studied by Van Huyck et al. (1990), in which players choose integer strategies 1-7 and earn payoffs increasing linearly in the group median and decreasing linearly in the squared deviation from the median; a traveler's dilemma game (Capra et al., 1999) in which players choose numbers from 80 to 200 and each player receives the a payoff equal to the minimum of the chosen numbers and the player who chose the low number receives a bonus of $R$ from the player who chose the high number; and a coordination game (Amaldoss and Ho, 2001) in which $n$ players simultaneously enter a large or small market and earn $2 n(n)$ divided by the number of entrants if they enter the large (small) market.
} 
self-tuning EWA can explain cross-game variation. Sampling widely is also a good way to test robustness of any model of learning or equilibrium. Models that are customized to explain one game are insightful, but not as useful as games which explain disparate patterns with one general model (see Roth and Erev, 1995; Goeree and Holt, 2001).

\subsection{Estimation method}

Consider a game where $N$ subjects play $T$ rounds. For a given player $i$, the likelihood function of observing a choice history of $\left\{s_{i}(1), s_{i}(2), \ldots, s_{i}(T-1), s_{i}(T)\right\}$ is given by:

$$
\Pi_{t=1}^{T} P_{i}^{s_{i}(t)}(t \mid \lambda)
$$

The joint likelihood function $L(\lambda)$ of observing all players' choice is given by

$$
L(\lambda)=\Pi_{i}^{N}\left\{\Pi_{t=1}^{T} P_{i}^{s_{i}(t)}(t \mid \lambda)\right\}
$$

To determine the predicted probabilities $P_{i}^{s_{i}(t)}(t \mid \lambda)$, we start with initial attractions $A_{i}^{j}(0)$ (which are the same for all $i$ ) determined by the predictions of the cognitive hierarchy model (Camerer, Ho and Chong, 2003, 2004) using $\tau=1.5 .{ }^{14}$ After each period, the functions $\phi_{i}(t)$ and $\delta_{i j}(t)$ are updated according to player $i$ 's experience and applied to the self-tuning EWA model (fixing $\lambda$ ) to determine updated attractions according to the EWA rule. The updated attractions produce predicted probabilities $P_{i}^{s_{i}(t)}(t \mid \lambda)$. Using the first $70 \%$ of the subjects in each game, we determine the value of $\lambda$ that maximizes the total likelihood over the $70 \%$ of the subjects. Then the value of $\lambda$ is frozen and used to forecast behavior of the entire path of the remaining $30 \%$ of the subjects. ${ }^{15}$ Payoffs were converted to inflation-adjusted dollars (which is important for cross-game forecasting) and scaled by subtracting the lowest possible payoffs. Randomized bootstrap resampling is used to calculate parameter standard errors. ${ }^{16}$

\footnotetext{
${ }^{14}$ In the games we study, for example, one-step behavior predicts choices of 35 in beauty contests, 7 in continental-divide games, 4 in median-action games, the large pot in entry-choice games, 5 and 4 in patentrace games for strong and weak players, and $200-2 R$ in traveler's dilemma games.

${ }^{15}$ We also tried using the first $70 \%$ of the observations from each subject, then forecasted the last $30 \%$. The results are similar.

${ }^{16}$ In the first few periods of a game, players often learn rapidly. To capture this, we smooth the $\phi_{i}(t)$ function by starting at 0.5 , and gently blending in the updated values according to $\hat{\phi}_{i}(t) \equiv .5 / t+(t-1) \phi_{i}(t) / t$ in the empirical implementation.
} 
In addition to self-tuning EWA, we estimated both the parametric EWA model and the oneparameter quantal response equilibrium (QRE) model. QRE is a static no-learning benchmark, which is a tougher competition than Nash equilibrium.

\subsection{Model fit and predictive accuracy}

The first question to address is how well models fit and predict on a game-by-game basis (i.e., when EWA parameters are estimated separately for each game). As noted, to limit overfitting we estimate parameters using $70 \%$ of the subjects (in-sample calibration) and use those estimates to predict choices by the remaining 30\% (out-of-sample validation). For in-sample estimation we report a Bayesian information criterion (BIC) which subtracts a penalty $\frac{k \cdot \ln (N T)}{2}$ from the $L(\lambda)$ value. For out-of-sample validation we report the log-likelihood $(L(\lambda))$ on the hold-out sample of $30 \%$ of the subjects.

Table 2 shows the results. The table also shows the choice probability implied by the average likelihood ${ }^{17}$ compared to the probability if choices were random. Across games, selftuning EWA predicts a little worse than EWA in out-of-sample prediction, though generally more accurately than QRE. This is not surprising since the parametric EWA model uses four extra free parameters $(\delta, \phi, \kappa$ and $N(0))$ in each game. The correlation between the $\phi$ function of self-tuning and the $\phi$ estimates of EWA is 0.77 and the corresponding correlation for the $\delta$ is $0.32 .{ }^{18}$ However, self-tuning EWA is better in the pooled estimation where a common set of parameters (except $\lambda$, which is always game-specific) was used for EWA. QRE fits worst in both individual games and pooled estimation, which is no surprise because it does not allow learning.

A more challenging robustness test is to estimate all parameters on six of the seven games, then use those parameters to predict choices in the remaining seventh game for all subjects. This is done for each of the seven games, one at a time. Cross-game prediction has been used by others but only within similar games in a class $(2 \times 2$ games with mixed equilibria, Erev and Roth, 1998; and 5x5 symmetric games, Stahl, 2000). Our results test whether fitting a model on a coordination game, say, can predict behavior in a game with mixed equilibrium. This

\footnotetext{
${ }^{17}$ That is, divide the total log likelihood by the number of subject-periods. Exponentiating this number gives the geometric mean ("average") predicted probability of the strategies that are actually played.

${ }^{18}$ The parameter estimates are reported in Table A.1.
} 
is the most ambitious use of learning models across games since Roth and Erev (1995) who demonstrated the importance of this kind of cross-game forecasting.

Table 3 reports results from the cross-game prediction. By this measure, self-tuning EWA has the highest cross-game likelihood in three games; EWA is highest in four other games. QRE is the least accurate in six out of the seven games.

Likelihood values summarize the model fit over time, strategies and subjects; but they do not allow one to gauge how model fit changes over time and across strategies. To get a more nuanced feel for the fit between data and models, the next section produces graphs using predicted and relative frequencies for three games which are exemplars of three classes: The patent race game has a unique mixed-strategy equilibrium, the continental divide coordination game has multiple Pareto-ranked pure equilibria, and the beauty contest games are dominance-solvable. ${ }^{19}$

\subsection{Games with unique mixed strategy equilibrium: Patent races}

In the patent race game two players, one strong and one weak, are endowed with resources and compete in a patent race. The strong player has an endowment of 5 units and the weak player has an endowment of 4 units (Rapoport and Amaldoss, 2000). They simultaneously invest an integer amount up to their endowments, $i_{\text {strong }}$ and $i_{\text {weak }}$. The player whose investment is strictly larger earns 10 minus their investment. A player whose investment is less than or equal to the other player's investment earns no payoff, and ends up with their endowment minus the investment.

The game has an interesting strategic structure. The strong player can guarantee a payoff of five by investing the entire endowment $i_{\text {strong }}=5$ (out-spending the weak player), which strictly dominates investing zero $\left(i_{\text {strong }}=0\right)$. Eliminating the strong player's dominated strategy $i_{\text {strong }}=0$ then makes $i_{\text {weak }}=1$ a dominated strategy for the weak player (since she can never win by investing one unit). Iterating in this way, the strong player deletes $i_{\text {strong }} \in\{0,2,4\}$ and the weak player deletes $i_{\text {weak }} \in\{1,3\}$ by iterated application of strict dominance. The result is a unique mixed equilibrium in which strong players invest five $60 \%$ of the time and play their other two (serially) undominated strategies of investing one and three $20 \%$ of the time, and weak players invest zero $60 \%$ of the time and invest either two or four $20 \%$ of the time.

\footnotetext{
${ }^{19}$ Corresponding graphs for all games can be seen at http://www.bschool.nus.edu.sg/Staff/bizcjk/fewa.htm so that readers can draw their own conclusions about other games.
} 
Thirty six pairs of subjects played the game in a random matching protocol 160 times (with the role switched after 80 rounds); the 36 pairs are divided into 2 groups where random matching occurs within group. Since overall choice frequencies do not change visibly across time, and are rather close to equilibrium predictions, our plots show frequencies of transitions between period $t-1$ and period $t$ strategies to focus on changes across time. Figures $2 \mathrm{a}-\mathrm{d}$ show the empirical transition matrix and predicted transition frequencies across the five strategies $\left(i_{\text {strong }} \in\{0,1, \cdots 5\}\right)$ for strong players, using the within-game estimation and pooling across all subjects. (Weak-player results are similar.)

The key features of the data are the high percentage of transitions from 5 to 5 , almost $40 \%$, and roughly equal numbers of transitions (about $5 \%$ ) from 1 to 1 , and from 1 to 5 or vice versa. The figures show that $\mathrm{QRE}$ does not predict differences in transitions at all. The challenge for explaining transitions is that after investing $i_{\text {strong }}=5$, about $80 \%$ of the time the strong player knows that the weak player invested only 0 or 2. Most learning models predict that strong players should therefore invest less, but the figures show that about half the time the strong players invest 5 again. The self-tuning and parametric EWA models explain the relatively low rate of downward transitions by multiplying the high foregone payoffs, in the case where the strong player invested 5 and the weak player invested nothing or two, by a relatively low value of $\delta$. This means the attractions for low $i_{\text {strong }}$ are not updated as much as the chosen strategy $i_{\text {strong }}=5$, which explains the persistence of investing and the low rate of switching. The low value of $\delta$, which is estimated to be .30 in EWA and averages .16 in self-tuning EWA, is one way of expressing why strong players are sluggish in switching down from $i_{\text {strong }}=5$.

\subsection{Games with multiple pure strategy equilibria: Continental divide game}

Van Huyck et al. (1997) studied a coordination game with multiple equilibria and extreme sensitivity to initial conditions, which we call the continental divide game (CDG).

Subjects play in cohorts of seven people. Subjects choose an integer from 1 to 14, and their payoff depends on their own choice and on the median choice of all seven players. The payoff matrix is constructed so that there are two pure equilibria (at 3 and 12) which are Paretoranked (12 pays $\$ 1.12$ and 3 pays $\$ .60$ ). The best-response correspondence bifurcates in the middle: For all $M \leq 7$, the best response to a median $M$ is strictly between $M$ and 3 . For high medians $M \geq 8$, the best response is strictly between $M$ and 12 . The payoff at 3 is about half 
as much as at 12. This game captures the possibility of extreme sensitivity to initial conditions (or path-dependence).

Their experiment used 10 cohorts of seven subjects each, playing for 15 periods. At the end of each period subjects learned the median, and played again with the same group in a partner protocol.

Figures 3a-d show empirical frequencies (pooling all subjects) and model predictions. The key features of the data are: Bifurcation over time from choices in the middle of the range (5-10) to the extremes, near the equilibria at 3 and 12; and late-period choices are more sharply clustered around 12 than around 3. (Figure 3a hides strong path-dependence: Groups which had first-period $M \leq 7$ ( $M \geq 8)$ always converged toward the low (high) equilibrium.) Notice also that strategies 1-4 are never chosen in early periods, but are frequently chosen in later periods; and oppositely, strategies 7-9 are frequently chosen in early periods but never chosen in later periods. A good model should be able to capture these subtle effects by "accelerating" low choices quickly (going from zero to frequent choices in a few periods) and "braking" midrange choices quickly (going from frequent 7-9 choices to zero).

QRE fits poorly because it predicts no movement. Self-tuning EWA and parametric EWA are fairly accurate and able to explain the key features of the data- viz., convergence toward the two equilibria, sharper convergence around 12 than around 3, and rapid increase in strategies 1-4 and extinction of 7-9. Both this game and the game above show how self-tuning EWA is able to reproduce the predictive power of EWA without having to estimate parameters.

\subsection{Games with dominance-solvable pure strategy equilibrium: p-Beauty Contests}

In the $p$-beauty contests of Ho et al. (1998), seven players simultaneously choose numbers in $[0,100]$. The player whose number is closest to a known fraction (either 0.7 or 0.9 ) of the group average wins a fixed prize. Their experiment also manipulated experience of subjects because half of them played a similar game before. Initial choices are widely dispersed and centered around 45 . When the game is repeated, numbers gradually converge toward the equilibrium 0 and experienced subjects converge much faster towards equilibrium.

Figures 4a-f show empirical frequencies and model predictions of self-tuning EWA and EWA broken down by experience of subjects. (As in the earlier plots, QRE fits badly so it is omitted.) 
Self-tuning EWA tracks behavior about as accurately as EWA for inexperienced subjects, and is substantially more accurate for experienced subjects. The cross-game EWA estimate of $\phi$ used is 0.83 , which is significantly higher than the in-game estimate $\phi$ of 0.31 . The cross-game estimate of $\delta$ used is 0.29 , lower than the in-game estimate $\delta$ of $0.70 .^{20}$ These cross-game values create the sluggishness in responding to surprises ( $\phi$ is too high) and to the many better strategies available ( $\delta$ is too low).

The average self-tuning function $\phi_{i}(t)$ is 0.58 , which is relatively more responsive to surprises than the 0.83 cross-game estimate. Coupled with the $\delta_{i j}(t)$ function, which by definition is totally responsive to better strategies, this helps to explain why self-tuning EWA predicts behavior better. The sluggish response to surprise of EWA also explains why EWA is less accurate than its self-tuning cousin in experienced session; experienced subjects create more surprises than their inexperienced counterparts as they move faster to convergence.

\section{Conclusion}

Learning is clearly important for economics. Equilibrium theories are useful because they suggest a possible limit point of a learning process and permit comparative static analysis. But if learning is slow, or the time path of behavior selects one equilibrium out of many, a precise theory of equilibration is crucial for knowing which equilibrium will result, and how quickly.

The theory described in this paper, self-tuning EWA, replaces the key parameters in the EWA learning models with functions that change over time in response to experience. One function is a "change detector" $\phi$ which goes up (limited by one) when behavior by other players is stable, and dips down (limited by zero) when there is surprising new behavior by others. When $\phi$ dips down, the effects of old experience (summarized in attractions which cumulate or average previous payoffs) is diminished by decaying the old attraction by a lot. The second "attention" function $\delta$ is one for strategies that yield better than actual payoff and zero otherwise. This function ties sensitivity to foregone payoffs to attention, which is likely to be on strategies that give better than actual payoff ex post. Self-tuning EWA is more parsimonious than most learning theories because it has only one free parameter- the response sensitivity $\lambda$.

\footnotetext{
${ }^{20}$ Both in-game and cross-game estimates are reported in the Table A.2.
} 
We report fit and prediction of data from seven experimental games using self-tuning EWA, the parameterized EWA model, and quantal response equilibrium (QRE). Both QRE and selftuning EWA have one free parameter, and EWA has five. We report both in-sample fit (penalizing more complex theories using the Bayesian information criterion) and out-of-sample as well as out-of-game predictive accuracy, to be sure that many complex models do not necessarily fit better.

There are two key results.

First, self-tuning EWA fits and predicts slightly worse than EWA in all seven games; and it produces a functional parameter values for $\phi$ and $\delta$ which roughly track the estimated values of fixed parameters across games. Self-tuning EWA therefore represents one solution to the central problem of flexibly generating EWA-like parameters across games. Because self-tuning EWA generates sensible cross-game parameter variation automatically, it fits and predicts better than other models when games are pooled and common parameters are estimated.

Second, the functions in self-tuning EWA seem to be robust across games. Our working paper added three brand new games which are not reported here (after the first version was written and circulated, and people were invited to submit games for analysis) to test robustness. The basic conclusions are replicated in these games, which have incomplete information and choices are made by groups rather than individuals (see our working paper).

A next step in this research is to find some axiomatic underpinnings for the functions. Extending the $\phi$ function to exploit information about ordered strategies might prove useful. And since self-tuning EWA is so parsimonious, it is useful as a building block for extending learning theories to include sophistication (players anticipating that others are learning; see Stahl, 1999) and explain "teaching" behavior in repeated games (Camerer, Ho and Chong 2002; Cooper and Kagel, 2004).

The self-tuning functions can also potentially do something that people do well- respond to changes in structural parameters of games over time (like demand shocks or the entry of new players) - which models that estimate parameters from history will do poorly. Since many naturally occurring economic games do have unanticipated shocks which change payoffs, exploring how people and models perform in games like this is worthwhile.

The theory is developed to fit experimental data, but the bigger scientific payoff will come from application to naturally-occurring situations. If learning is slow, a precise theory of eco- 
nomic equilibration is just as useful for predicting what happens in the economy as a theory of equilibrium. For example, institutions for matching medical residents and medical schools, and analogous matching in college sororities and college bowl games, developed over decades (Roth and Xing, 1994). Bidders in eBay auctions learn to bid late to hide their information about an object's common value (Bajari and Hortacsu, 2003). Consumers learn over time what products they like (Ho and Chong, 2003). Learning in financial markets can generate excess volatility and returns predictability, which are otherwise anomalous in rational expectations models (Timmerman, 1993). Sargent (1999) argues that learning by policymakers about expectational Phillips' curves and the public's perceptions of inflation explains macroeconomic behavior in the last couple of decades. Good theories of learning should be able to explain these patterns and help predict how new institutions will evolve, how rapidly bidders learn to wait, and which new products will succeed. Applying self-tuning EWA, and other learning theories, to field domains is therefore an important goal of future research.

\section{References}

[1] Amaldoss, Wilfred and Teck-Hua Ho, "EWA Learning in Games with Different Group Sizes," Marketing Department Working Paper, The Wharton School, 2001.

[2] Arifovic, Jasmina and John Ledyard, "Computer Testbeds: The Dynamics of GrovesLedyard Mechanisms," unpublished manuscript, 2002.

[3] Arthur, Brian, "Designing Economic Agents That Act Like Human Agents: A Behavioral Approach to Bounded Rationality," American Economic Review, 81(2), (1991), pp. 353359.

[4] Bajari, Patrick and Ali Hortacsu, "Winner's Curse, Reserve Prices and Endogenous Entry: Empirical Insights from Ebay Auctions," Rand Journal of Economics, 34(2), (2003), pp. 329-355.

[5] Bush, Robert R. and Frederick Mosteller, Stochastic models for learning, New York: Wiley, 1955.

[6] Cabrales, Antonio, Rosemarie Nagel and Roc Armenter, "Equilibrium Selection through Incomplete Information in Coordination Games: An Experimental Study," Universitat Pompeu Fabra working paper, 2002. 
[7] Camerer, Colin F., Behavioral Game Theory: Experiments on Strategic Interaction, Princeton:Princeton University Press, 2003.

[8] Camerer, Colin F. and Teck-Hua Ho, "Experience Weighted Attraction Learning in Normal Form Games," Econometrica, 67, (1999), pp. 827-873.

[9] Camerer, Colin F., Teck-Hua Ho and Juin-Kuan Chong, "Sophisticated EWA Learning and Strategic Teaching in Repeated Games," Journal of Economic Theory, 104, (2002), pp. 137-188.

[10] Camerer, Colin F., Teck-Hua Ho and Juin-Kuan Chong, "Models of Thinking, Learning and Teaching Games," The American Economic Review, 93(2), (2003), pp. 192-195.

[11] Camerer, Colin F., Teck-Hua Ho and Juin-Kuan Chong, "A Cognitive Hierarchy Model of Games," Quarterly Journal of Economics, 119(3), (2004), pp. 861-898.

[12] Capra, Monica, Jacob Goeree, Rosario Gomez and Charles Holt, "Anomalous Behavior in a Traveler's Dilemma," American Economic Review, 89(3), (1999), pp. 678-690.

[13] Cheung, Yin-Wong and Daniel Friedman, "Individual Learning in Normal Form Games: Some Laboratory Results," Games and Economic Behavior, 19, (1997), pp. 46-76.

[14] Chong, Juin-Kuan, Teck Ho and Colin F. Camerer, "A Learning-based Model of Repeated Games with Incomplete Information," Games and Economic Behavior, (2005), in press.

[15] Cooper, David and John Kagel, "Learning and Transfer in Signaling Games," working paper, Department of Economics, Case Western Reserve University, 2004.

[16] Costa-Gomes, M. and V. Crawford and B. Broseta, "Cognition and Behavior in Normalform Games: An Experimental Study," Econometrica, 69, (2001), 1193-1235.

[17] Cross, John, A Theory of Adaptive Learning Economic Behavior, New York: Cambridge University Press, 1983.

[18] Erev, Ido and Alvin E. Roth, "Predicting How People Play Games: Reinforcement Learning in Experimental Games with Unique, Mixed Strategy Equilibria," American Economic Review, 88(4), (1998), pp. 848-81.

[19] Erev, Ido, Yoella Bereby-Meyer and Alvin E. Roth, "The Effect of Adding a Constant to All Payoffs: Experimental Investigation, and a Reinforcement Learning Model with 
Self-Adjusting Speed of Learning," Journal of Economic Behavior and Organization, 39, (1999), pp. 111-128.

[20] Frechette, Guillaume, "Learning in A Multilateral Bargaining Experiment," Harvard University working paper, 2003. http://www.people.hbs.edu/ gfrechette/ print/ frechette_learning.pdf

[21] Fudenberg, Drew and David K. Levine, The Theory of Learning in Games, Boston: MIT Press, 1998.

[22] Goeree, J. K. and C. A. Holt, "Ten little treasures of game theory, and ten intuitive contradictions," American Economic Review, 91(6), (2001), pp. 1402-1422

[23] Hart, Sergiu and Andreu Mas-Colell, "A General Class of Adaptive Strategies," Journal of Economic Theory, 98, (2001), pp. 26-54.

[24] Harley, Calvin, "Learning the Evolutionary Stable Strategies," Journal of Theoretical Biology, 89, (1981), pp. 611-633.

[25] Heller, Dana and Rajiv Sarin, "Parametric Adaptive Learning," University of Chicago Working Paper, 2000.

[26] Ho, Teck-Hua, Colin F. Camerer, Colin and Juin-Kuan Chong, "Economic Value of fEWA: A Functional Theory of Learning in Games," 2001. http://www.bschool.nus.edu.sg/ Staff/bizcjk/fewa.htm

[27] Ho, Teck-Hua, Colin F. Camerer and Keith Weigelt, "Iterated Dominance and Iterated Best Response in Experimental "p-Beauty Contests"," American Economic Review, 88, (1998), pp. 947-969.

[28] Ho, Teck-Hua and Juin-Kuan Chong, "A Parsimonious Model of SKU Choice," Journal of Marketing Research, 40(3), (2003), pp. 351-65.

[29] Ho, Teck-Hua, Xin Wang and Colin F. Camerer, "Individual Differences in the EWA Learning with Partial Payoff Information," Working Paper, University of California Berkeley, 2004.

[30] Hopkins, Edward, "Two Competing Models of how People Learn in Games," Econometrica, 70(6), (2002), pp. 2141-2166. 
[31] Josephson, Jens, "A Numerical Analysis of the Evolutionary Stability of Learning Rules," Stockholm School of Economics SSE/EFI paper no. 474, 2001. http://swopec.hhs.se/hastef/abs/hastef0474.htm.

[32] Kocher, Martin and Matthias Sutter, "The Decision Maker Matters: Individual versus Group Behavior in Experimental Beauty-Contest Games," The Economic Journal, 115, (2005), pp. 200-223.

[33] Marcet, Albert and Juan Pablo Nicolini, "Recurrent Hyperinflations and Learning," American Economic Review, 93(5), (2003), pp. 1476-.

[34] McAllister, Patrick H., "Adaptive Approaches to Stochastic Programming," Annals of Operations Research, 30, (1991), pp. 45-62.

[35] McKelvey, Richard and Thomas Palfrey, "Quantal Response Equilibria for Normal Form Games," Games and Economic Behavior, 10, (1995), pp. 6-38.

[36] Mookerjhee, Dilip, and Barry Sopher, "Learning Behavior in an Experimental Matching Pennies Game," Games and Economic Behavior, 7, (1994), pp. 62-91.

[37] Mookerjhee, Dilip, and Barry Sopher, "Learning and Decision Costs in Experimental Constant-sum Games," Games and Economic Behavior, 19, (1997), pp. 97-132.

[38] Nyarko, Yaw, and Andrew Schotter, "An Experimental Study of Belief Learning Using Elicited Beliefs," Econometrica, Vol. 70, No. 3 (May, 2002), pp. 971-1005

[39] Rapoport, Amnon and Ido Erev, "Coordination, "magic", and reinforcement learning in a market entry game," Games and Economic Behavior, 23, (1998), pp. 146-175.

[40] Rapoport, Amnon and Wilfred Amaldoss, "Mixed Strategies and Iterative Elimination of Strongly Dominated Strategies: An Experimental Investigation of States of Knowledge," Journal of Economic Behavior and Organization, 42, (2000), pp. 483-521.

[41] Roth, Alvin E. and Xiaolin Xing, "Jumping the Gun: Imperfections and Institutions Related to the Timing of Market Transactions," American Economic Review, 84, (1994), pp. 992-1044.

[42] Roth, Alvin E. and Ido Erev, "Learning in Extensive-Form Games: Experimental Data and Simple Dynamic Models in the Intermediate Term," Games and Economic Behavior, 8(1), (1995), pp. 164-212. 
[43] Sarin, Rajiv and Farshid Vahid, "Predicting How People Play Games: A Simple Dynamic Model of Choice," Games and Economic Behavior, 34, (2001), pp. 104-122.

[44] Sarin, Rajiv and Farshid Vahid, "Strategy Similarity and Coordination," Economic Journal, forthcoming, (2003).

[45] Sargent, Thomas, The Conquest of American Inflation, Princeton: Princeton University Press, 1999.

[46] Selten, Reinhard and Rolf Stoecker, "End Behavior in Sequences of Finite Prisoner's Dilemma Supergames: A Learning Theory Approach," Journal of Economic Behavior and Organization, 7, (1986), pp. 47-70.

[47] Sovik, Ylva, "Impossible Bets: An Experimental Study," University of Oslo working paper, 2001.

[48] Stahl, Dale O., "Sophisticated Learning and Learning Sophistication," University of Texas at Austin Working Paper, 1999.

[49] Stahl, Dale O, "Rule Learning in Symmetric Normal-Form Games: Theory and Evidence," Games and Economic Behavior, 32(1), (2000), pp. 105-138.

[50] Stahl, Dale O. and P. Wilson, "On Players Models of Other Players: Theory and Experimental Evidence," Games and Economic Behavior, 10, (1995), 213-54.

[51] Sutton, Richard and Andrew Barto, Reinforcement Learning: An Introduction, Boston: MIT Press, 1998.

[52] Timmerman, Allan G, "How Learning in Financial Markets Generates Excess Volatility and Predictability in Stock Prices.' Quarterly Journal of Economics, 108, (1993), pp. 11351145.

[53] Van Huyck, John, Raymond Battalio and Richard Beil, "Tacit Cooperation Games, Strategic Uncertainty, and Coordination Failure," The American Economic Review, 80, (1990), pp. 234-248.

[54] Van Huyck, John, Raymond Battalio and Frederick Rankin, "Selection Dynamics and Adaptive Behavior Without Much Information," Working Paper, Department of Economics, Texas A \& M University, 2005. 
[55] Van Huyck, John, Joseph Cook and Raymond Battalio, "Adaptive Behavior and Coordination Failure," Journal of Economic Behavior and Organization, 32, (1997), pp. 483-503.

[56] Wilcox, Nathaniel T., "Heterogeneity and Learning Principles," University of Houston working paper, 2003. http://www.uh.edu/ñwilcox/papers/hetero_and_learning_W.pdf 
Table 1: A Description of the Seven Games Used in the Estimation of Various Learning Models

\begin{tabular}{|c|c|c|c|c|c|c|c|c|}
\hline Game & $\begin{array}{c}\text { Number of } \\
\text { Players }\end{array}$ & $\begin{array}{l}\text { Number of } \\
\text { Strategies }\end{array}$ & $\begin{array}{l}\text { Number of Pure } \\
\text { Strategy Equilibria }\end{array}$ & $\begin{array}{l}\text { Number of } \\
\text { Subjects }\end{array}$ & $\begin{array}{l}\text { Number of } \\
\text { Rounds }\end{array}$ & $\begin{array}{l}\text { Matching } \\
\text { Protocol }\end{array}$ & $\begin{array}{c}\text { Experimental } \\
\text { Treatment }\end{array}$ & Description of Games \\
\hline $\begin{array}{l}\text { Mixed Strategies } \\
\text { Mookerjhee and Sopher (1997) }\end{array}$ & 2 & 4,6 & 0 & 80 & 40 & Fixed & Stake Size & $\begin{array}{l}\text { A constant-sum game with unique mixed } \\
\text { strategy equilibrium. }\end{array}$ \\
\hline $\begin{array}{l}\text { Patent Race } \\
\text { Rapoport and Amaldoss (2000) }\end{array}$ & 2 & 5,6 & 0 & 36 & 80 & Random & Strong vs Weak & $\begin{array}{l}\text { Strong (weak) player invests between } \\
0 \text { and } 5 \text { ( } 0 \text { and } 4) \text { and the higher investment } \\
\text { wins a fixed prize. }\end{array}$ \\
\hline $\begin{array}{l}\text { Continental Divide } \\
\text { Van Huyck et al. (1997) }\end{array}$ & 7 & 14 & 2 & 70 & 15 & Fixed & None & $\begin{array}{l}\text { A coordination game with two pure strategy } \\
\text { equilibria }\end{array}$ \\
\hline $\begin{array}{l}\text { Median Action } \\
\text { Van Huyck et al. (1990) }\end{array}$ & 9 & 7 & 7 & 54 & 10 & Fixed & None & $\begin{array}{l}\text { A order-statistic game with individual payoff } \\
\text { decreases in the distance between individual } \\
\text { choice and the median }\end{array}$ \\
\hline $\begin{array}{l}\text { Pot Games } \\
\text { Amaldoss and Ho (2001) }\end{array}$ & $3,6,9,18$ & 2 & 1 & 84 & $\begin{array}{l}25 \text { (manual) } \\
28 \text { (computer) }\end{array}$ & Fixed & Number of Players & $\begin{array}{l}\text { An entry game where players must decide } \\
\text { which of the two ponds of sizes } 2 n \text { and } n \\
\text { they wish to enter. Payoff is the ratio of the pond } \\
\text { size and number of entries. }\end{array}$ \\
\hline $\begin{array}{l}\text { Price Matching } \\
\text { (Traveller's Dilemma) } \\
\text { Capra et al. (1999) }\end{array}$ & 2 & $121^{1}$ & 1 & 52 & 10 & Random & Penalty Size & $\begin{array}{l}\text { Players choose claims between } 80 \text { and } 200 \text {. } \\
\text { Both players get lower claim but the high-claim } \\
\text { player pays a penalty to the low-claim player. }\end{array}$ \\
\hline $\begin{array}{l}\text { p-Beauty Contest } \\
\text { Ho et al. (1998) }\end{array}$ & 7 & 101 & 1 & 196 & 10 & Fixed & Experienced vs. Inexperienced & $\begin{array}{l}\text { Players simultaneously choose a number } \\
\text { from } 0 \text { to } 100 \text { and the winner whose number is } \\
\text { closet to } p(<1) \text { times the group average }\end{array}$ \\
\hline
\end{tabular}


Table 2: Model Fit

\begin{tabular}{|c|c|c|c|c|c|c|c|c|}
\hline Data Set & $\begin{array}{c}\text { Mixed } \\
\text { Strategies }\end{array}$ & $\begin{array}{l}\text { Patent } \\
\text { Race }\end{array}$ & $\begin{array}{c}\text { Continental } \\
\text { Divide }\end{array}$ & $\begin{array}{l}\text { Median } \\
\text { Action }\end{array}$ & $\begin{array}{c}\text { Pot } \\
\text { Games }\end{array}$ & $\begin{array}{c}\text { p-Beauty } \\
\text { Contest }\end{array}$ & $\begin{array}{c}\text { Price } \\
\text { Matching }\end{array}$ & Pooled $^{2}$ \\
\hline Total Sample Size & 3200 & 5760 & 1050 & 540 & 2217 & 1960 & 520 & 15247 \\
\hline \multicolumn{9}{|c|}{ In-sample Calibration } \\
\hline Sample Size & 2240 & 4000 & 735 & 380 & 1478 & 1380 & 360 & 10573 \\
\hline \multicolumn{9}{|c|}{ BIC (Bayesian Information Criterion) ${ }^{1}$} \\
\hline Self-tuning EWA & -3206 & -4367 & -1203 & -309 & -938 & -5184 & -1451 & -16672 \\
\hline EWA & -3040 & -4399 & -1091 & -293 & -931 & -4987 & -1103 & -16646 \\
\hline QRE & -3442 & -6686 & -1923 & -549 & -1003 & -6254 & -1420 & -21285 \\
\hline \multicolumn{9}{|c|}{ Average Probability } \\
\hline Self-tuning EWA & $23.9 \%$ & $33.6 \%$ & $19.5 \%$ & $44.6 \%$ & $53.1 \%$ & $2.3 \%$ & $1.8 \%$ & \\
\hline EWA & $26.0 \%$ & $33.5 \%$ & $23.2 \%$ & $48.1 \%$ & $53.9 \%$ & $2.7 \%$ & $4.9 \%$ & \\
\hline QRE & $21.6 \%$ & $18.8 \%$ & $7.3 \%$ & $23.8 \%$ & $50.8 \%$ & $1.1 \%$ & $2.0 \%$ & \\
\hline Random & $20.4 \%$ & $18.3 \%$ & $7.1 \%$ & $14.3 \%$ & $50.0 \%$ & $1.0 \%$ & $0.8 \%$ & \\
\hline \multicolumn{9}{|c|}{ Out-of-sample Validation } \\
\hline Sample Size & 960 & 1760 & 315 & 160 & 739 & 580 & 160 & 4674 \\
\hline \multicolumn{9}{|l|}{ Log-likelihood } \\
\hline Self-tuning EWA & -1394 & -1857 & -522 & -94 & -441 & -2348 & -586 & -7246 \\
\hline EWA & -1342 & -1876 & -482 & -89 & -433 & -2203 & -532 & -7366 \\
\hline QRE & -1441 & -3006 & -829 & -203 & -486 & -2667 & -607 & -9240 \\
\hline
\end{tabular}

Note 1: BIC (Bayesian Information Criterion) is given by $L L-(k / 2)^{\star} \log \left(N^{*} T\right)$ where $k$ is the number of parameters, $N$ is the number of subjects and $T$ is the number of periods. Note 2: A common set of parameters, except game-specific $\lambda$, is estimated for all games. Each game is given equal weight in LL estimation. 
Table 3: Out-of-sample Prediction Using Out-game Estimates

\begin{tabular}{lccccccc} 
Data Set & $\begin{array}{c}\text { Mixed } \\
\text { Strategies }\end{array}$ & $\begin{array}{c}\text { Patent } \\
\text { Race }\end{array}$ & $\begin{array}{c}\text { Continental } \\
\text { Divide }\end{array}$ & $\begin{array}{c}\text { Median } \\
\text { Action }\end{array}$ & $\begin{array}{c}\text { Pot } \\
\text { Games }\end{array}$ & $\begin{array}{c}\text { p-Beauty } \\
\text { Contest }\end{array}$ & $\begin{array}{c}\text { Price } \\
\text { Matching }\end{array}$ \\
\hline Total Sample Size & 3200 & 5760 & 1050 & 540 & 2217 & 1960 & 520 \\
Log-likelihood & & & & & & & \\
Self-tuning EWA & -4602 & -7114 & -1723 & -419 & -1399 & -8282 & -2192 \\
EWA & -4733 & -6321 & -1839 & -457 & -1365 & -7806 & -2140 \\
QRE & -4667 & -9132 & -2758 & -957 & -1533 & -8911 & -2413 \\
Average Probability & & & & & & & \\
Self-tuning EWA & $23.7 \%$ & $29.1 \%$ & $19.4 \%$ & $46.0 \%$ & $53.2 \%$ & $1.5 \%$ & $1.5 \%$ \\
Random & $20.4 \%$ & $18.3 \%$ & $7.1 \%$ & $14.3 \%$ & $50.0 \%$ & $1.0 \%$ & $0.8 \%$
\end{tabular}


Table A.1: Parameter Estimates

\begin{tabular}{|c|c|c|c|c|c|c|c|c|}
\hline Data Set & $\begin{array}{c}\text { Mixed } \\
\text { Strategies } \\
\end{array}$ & $\begin{array}{c}\text { Patent } \\
\text { Race }\end{array}$ & $\begin{array}{c}\text { Continental } \\
\text { Divide }\end{array}$ & $\begin{array}{l}\text { Median } \\
\text { Action }\end{array}$ & $\begin{array}{c}\text { Pot } \\
\text { Games }\end{array}$ & $\begin{array}{c}\text { p-Beauty } \\
\text { Contest }\end{array}$ & $\begin{array}{c}\text { Price } \\
\text { Matching } \\
\end{array}$ & Pooled \\
\hline \multicolumn{9}{|c|}{ Self-tuning EWA } \\
\hline$\phi$ function & 0.89 & 0.89 & 0.69 & 0.85 & 0.80 & 0.58 & 0.63 & 0.76 \\
\hline$\delta$ function & 0.17 & 0.16 & 0.47 & 0.21 & 0.23 & 0.38 & 0.59 & 0.32 \\
\hline$\lambda$ & 4.13 & 9.24 & 4.45 & 5.64 & 7.34 & 2.39 & 10.02 & 5.87 \\
\hline \multicolumn{9}{|l|}{ EWA } \\
\hline$\phi$ & 0.97 & 0.91 & 0.72 & 0.73 & 0.86 & 0.31 & 0.80 & 0.79 \\
\hline$\delta$ & 0.19 & 0.30 & 0.90 & 0.94 & 0.00 & 0.70 & 0.40 & 0.41 \\
\hline$\kappa$ & 0.82 & 0.15 & 0.77 & 0.99 & 0.92 & 0.91 & 0.80 & 0.28 \\
\hline N0 & 0.67 & 0.73 & 0.36 & 0.14 & 0.00 & 0.17 & 0.39 & 0.77 \\
\hline$\lambda$ & 0.34 & 4.27 & 13.83 & 18.55 & 1.61 & 2.57 & 9.88 & 6.33 \\
\hline \multicolumn{9}{|l|}{ QRE } \\
\hline$\lambda$ & 1.12 & 0.81 & 1.83 & 28.45 & 3.37 & 0.69 & 29.83 & 9.44 \\
\hline
\end{tabular}


Table A.2: Parameter Comparison of Self-tuning EWA with In-game and Out-game EWA

\begin{tabular}{|c|c|c|c|c|c|c|c|}
\hline Data Set & $\begin{array}{c}\text { Mixed } \\
\text { Strategies } \\
\end{array}$ & $\begin{array}{c}\text { Patent } \\
\text { Race }\end{array}$ & $\begin{array}{c}\text { Continental } \\
\text { Divide }\end{array}$ & $\begin{array}{c}\text { Median } \\
\text { Action } \\
\end{array}$ & $\begin{array}{c}\text { Pot } \\
\text { Games }\end{array}$ & $\begin{array}{c}\text { p-Beauty } \\
\text { Contest }\end{array}$ & $\begin{array}{c}\text { Price } \\
\text { Matching } \\
\end{array}$ \\
\hline$\phi$ function (Self-tuning EWA) & 0.89 & 0.89 & 0.69 & 0.85 & 0.80 & 0.58 & 0.63 \\
\hline In-game $\phi$ (EWA) & 0.97 & 0.91 & 0.72 & 0.73 & 0.86 & 0.31 & 0.80 \\
\hline Out-game $\phi$ (EWA) & 0.81 & 0.85 & 0.83 & 0.84 & 0.83 & 0.83 & 0.81 \\
\hline$\delta$ function (Self-tuning EWA) & 0.17 & 0.16 & 0.47 & 0.21 & 0.23 & 0.38 & 0.59 \\
\hline In-game $\delta$ (EWA) & 0.19 & 0.30 & 0.90 & 0.94 & 0.00 & 0.70 & 0.40 \\
\hline Out-game $\delta$ (EWA) & 0.50 & 0.40 & 0.29 & 0.29 & 0.31 & 0.29 & 0.43 \\
\hline
\end{tabular}




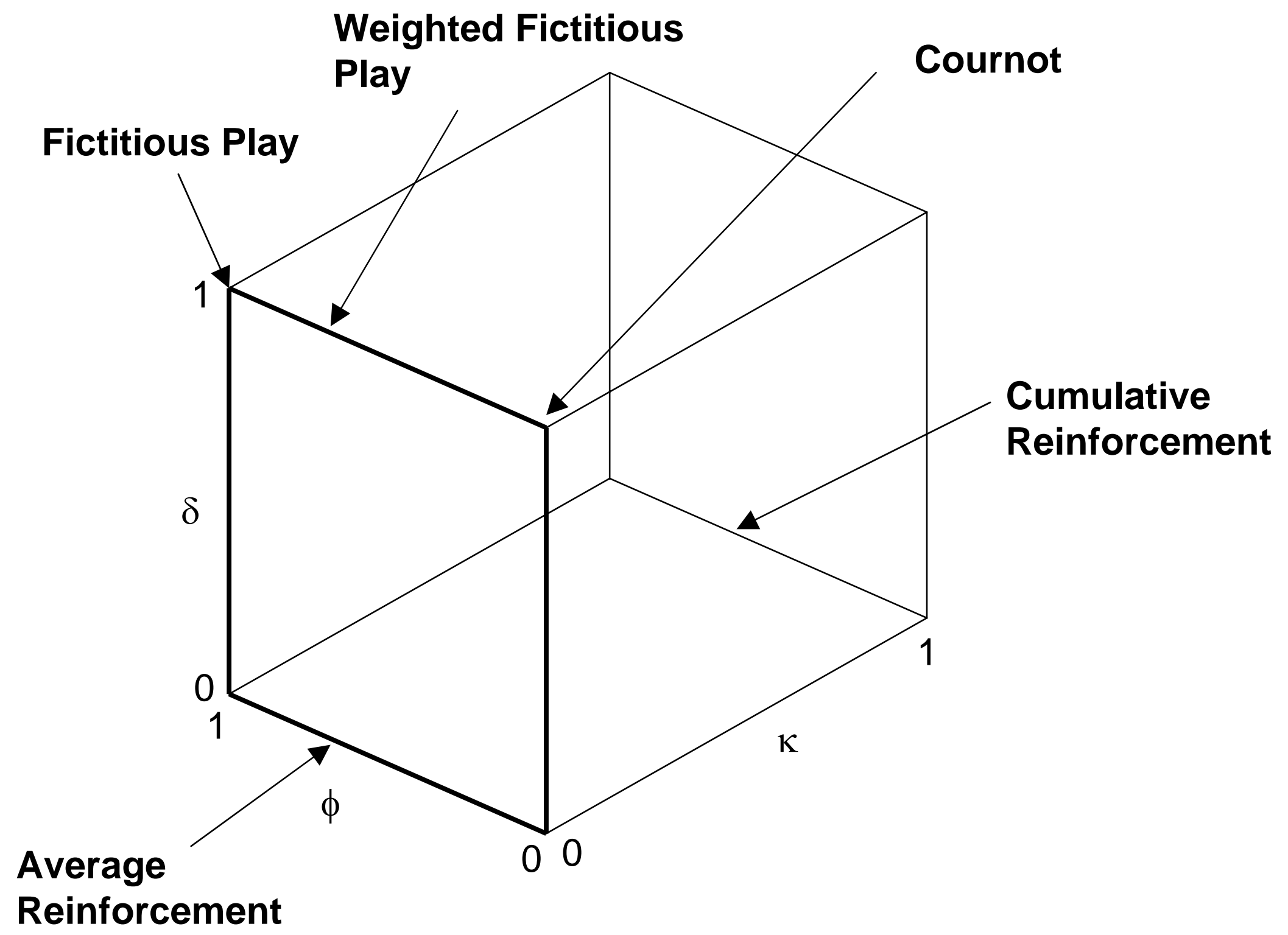

Figure 1: The EWA Learning Cube 


\section{Figure 2 Transition Matrices for Patent Race}

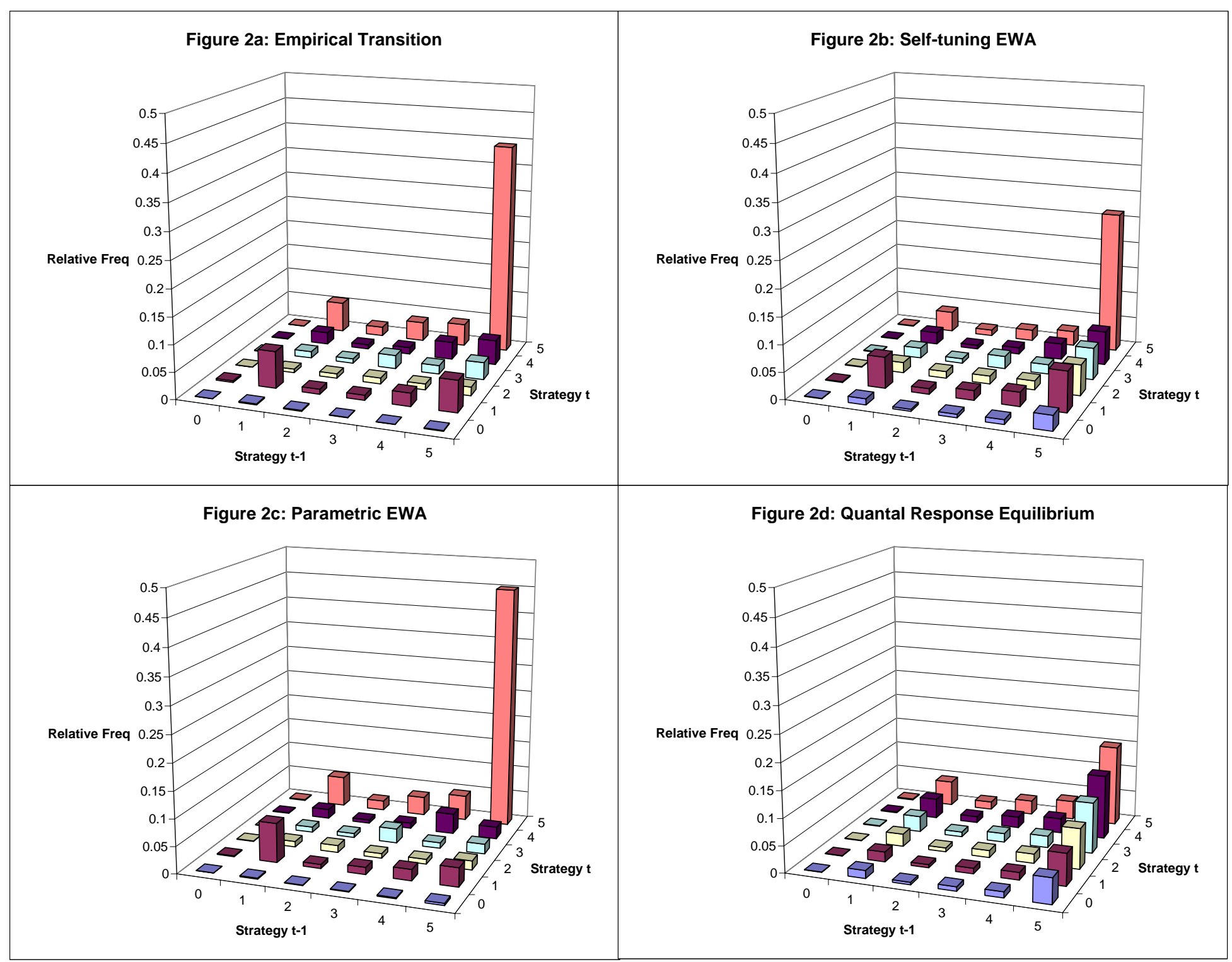




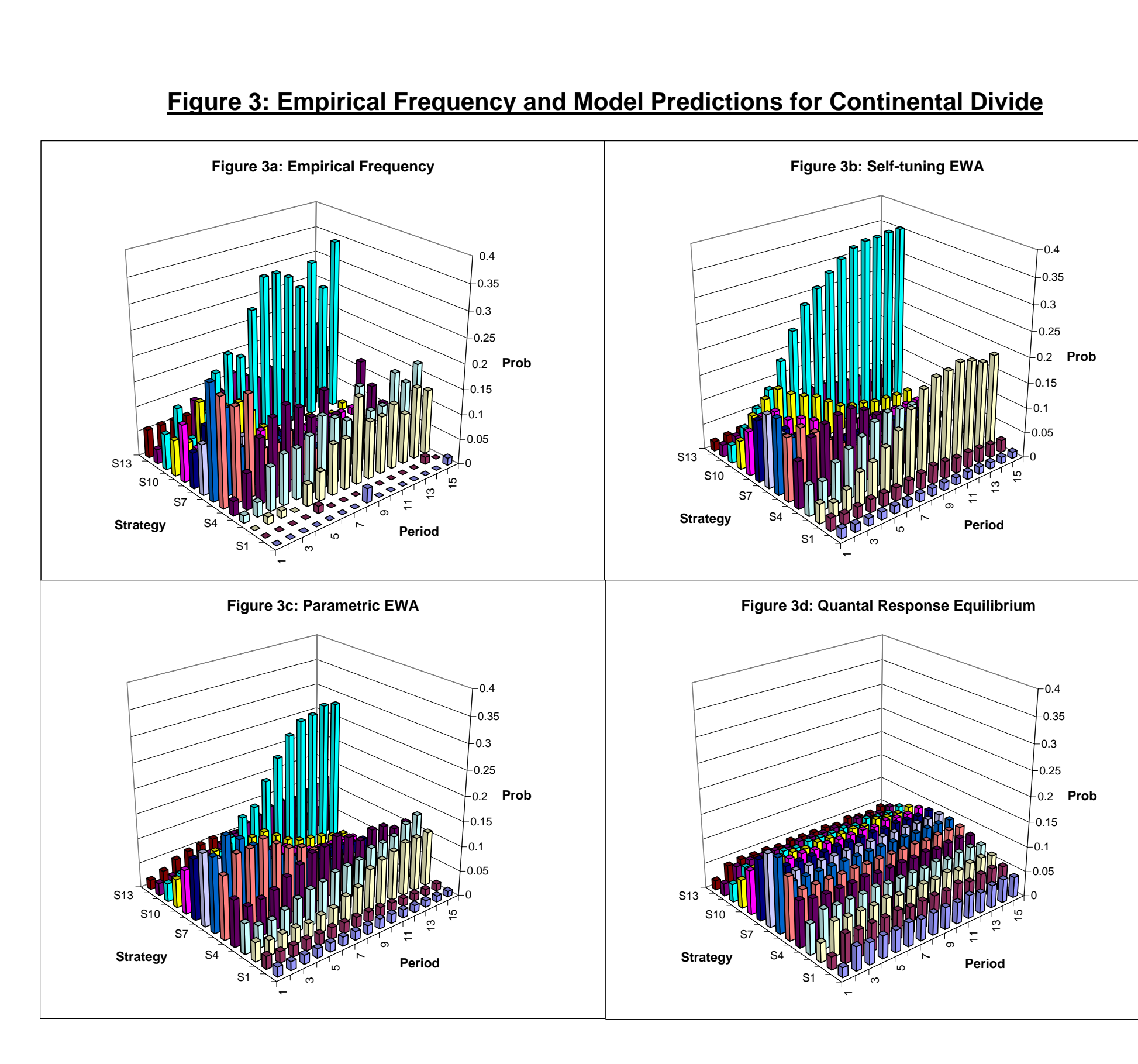


Figure 4: Empirical Frequency and Model Predictions for p-Beauty Contest

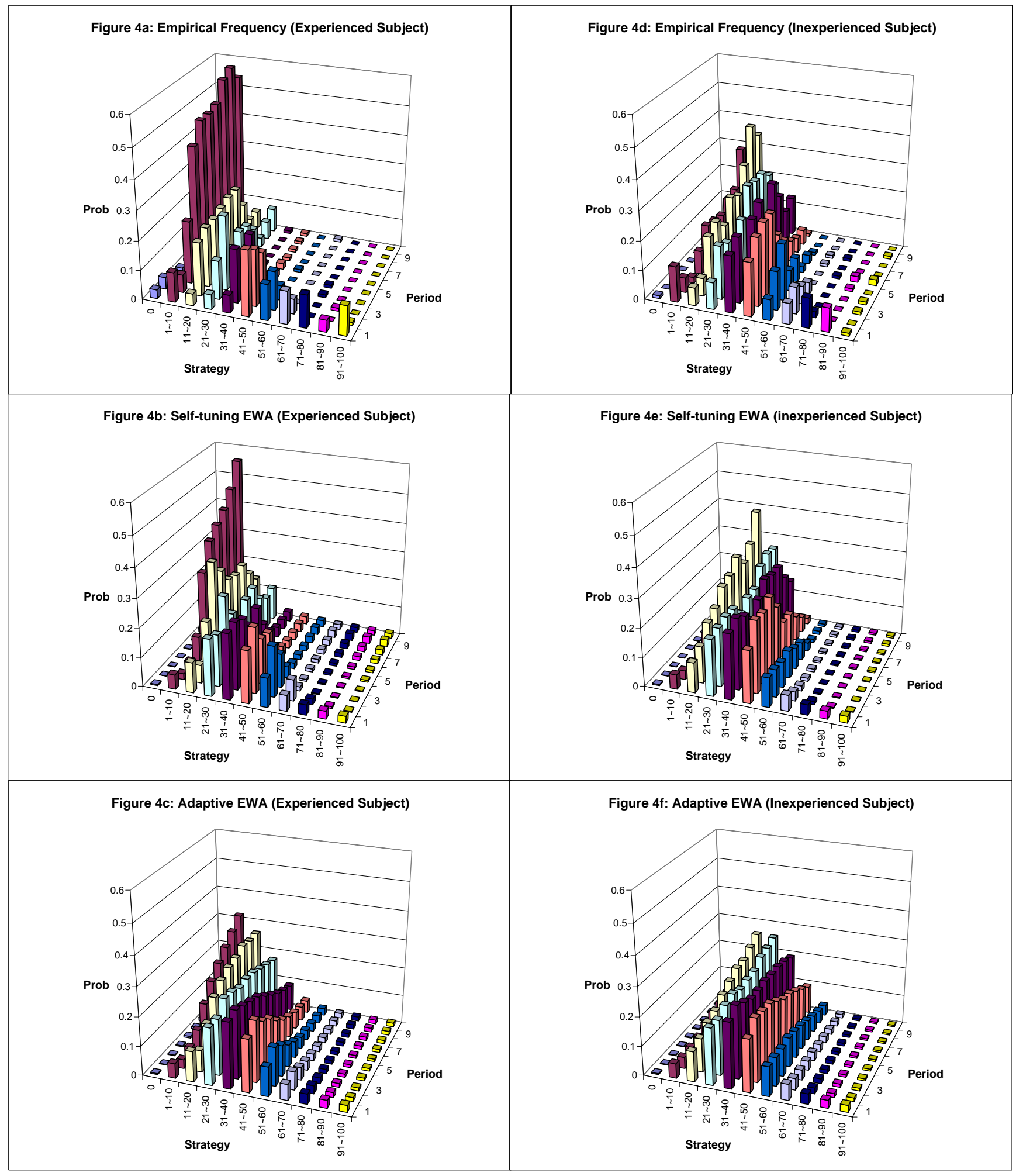

